\title{
O COMÉRCIO JUSTO COMO AGENTE MITIGADOR DAS MUDANÇAS CLIMÁTICAS: O CASO DO ALGODÃO ECOLÓGICO
}

\author{
Marilia Bonzanini Bossle \\ Doutoranda em Administração pela UFRGS \\ mariliabossle@gmail.com \\ Luís Felipe Nascimento \\ Professor na Escola de Administração da UFRS \\ nascimentolf@gmail.com \\ Marcelo Trevisan
}

Docente do Departamento de Ciências Administrativas da UFSM

marcelotrev@gmail.com

Paola Schmitt Figueiró

Doutoranda em Administração pela UFRGS

paola.adm@hotmail.com

Recebido em 10/agosto/2011

Aprovado em 05/setembro/2012

\section{RESUMO}

O Comércio Justo é uma configuração comercial orientada ao desenvolvimento sustentável, com melhores condições de trocas, promovendo a preservação do meio ambiente e proporcionando melhores condições aos produtores. Nesta pesquisa, objetivou-se evidenciar como o Comércio Justo pode contribuir para mitigar os efeitos das mudanças climáticas. A pesquisa foi realizada em duas etapas, a primeira exploratória, em busca de exemplos práticos relatados na teoria e a segunda, descritiva onde coletaram-se dados junto a organizações de Comércio Justo que integram a cadeia do algodão agroecológico. Este algodão é produzido com o uso de técnicas agrícolas sustentáveis e possui certificação de orgânico e de Comércio Justo. Os resultados sugerem que o Comércio Justo pode ser uma alternativa capaz de amenizar os efeitos nocivos da produção em grandes escalas e intensiva no uso de agroquímicos. São evidenciados os avanços observados nesse sentido, assim como apresenta-se as carências que ainda devem ser trabalhadas.

Palavras-chave: Comércio Justo, mitigação das mudanças climáticas, agroecologia, algodão ecológico, orgânico.

\section{ABSTRACT}

Fair Trade is an alternative business approach oriented to Sustainable Development, with better exchanges conditions, furthering the preservation of the environment and providing better conditions for producers. The main focus of this research is to highlight how Fair Trade can contribute to mitigating the effects of climate change. The research was conducted in two stages, first an exploratory phase, to seek practical examples reported in the theory and the second, when descriptive data were collected within organizations which are part of Fair Trade cotton agroecological chain. This cotton is produced using sustainable agricultural techniques and is certified organic and Fair Trade. The results suggest that Fair Trade can be an alternative to mitigate the harmful effects of production on large scales and the intensive use of agrochemicals. We highlighted the advances made in this direction, as well as the needs that still must be worked out.

Key-words: Fair Trade, climate change mitigation, ago ecology, ecological cotton, organic. 


\section{INTRODUÇão}

A produção intensiva e o consumismo estão provocando sérios danos ao planeta, o que tem estimulado o surgimento de novos modelos de produção e consumo. Além disso, para combater o fato de que o preço final das mercadorias nem sempre representa o valor despendido em todas as etapas da cadeia, foram desenvolvidas novas formas de relação entre os elos de uma cadeia produtiva. Algumas experiências demonstram que é possível fazer com que os consumidores, produtores, empresas, sociedade, governo e outras instituições trabalhem juntos para que o crescimento econômico também leve em consideração o desenvolvimento social e ambiental.

Essa produção intensiva feita do modo convencional costuma fazer uso de insumos químicos ou geneticamente modificados para o combate de pragas e para o crescimento acelerado das plantações. Tal modo de produção pode induzir a alterações de temperatura, conforme relatório do Intergovernmental Panel on Climate Change (IPCC, 2007), em camadas constantemente congeladas no Ártico, as temperaturas vêm elevando-se em até $3^{\circ} \mathrm{C}$ desde a década de 1980. O IPCC (2007) destaca ainda que, principalmente por causa da agricultura, desde 1750 verifica-se maior concentração de óxido nitroso e de gás metano na atmosfera, o que causa uma maior degradação do solo, contribuindo com as mudanças climáticas observadas ao longo das últimas décadas no planeta.

Nesse contexto, destaca-se a importância do conceito de Comércio Justo, que tem por objetivo promover o desenvolvimento econômico, organizativo, social e político integral. Um conceito ainda pouco conhecido no Brasil, mas que tende a se desenvolver. No Comércio Justo o consumidor consciente estabelece também relações de compromisso com os produtores. Ele faz questão de estar informado sobre a origem dos produtos, seu conteúdo ético e ambiental (FRETEL; SIMONCELLI-BOURQUE, 2003).

As associações de Comércio Justo estimulam que os produtores adotem certificações por meio de selos orgânicos, pois dentre as suas exigências está a prática dos princípios da agroecologia. Apoiar determinados modos de produção agrícola permite melhor adaptação às mudanças climáticas e à captação de carbono. O Comércio Justo encoraja os modos produtivos sustentáveis, dentro da produção orgânica, florestas sustentáveis, rotação de culturas, integração da agricultura e pecuária, técnicas de estocagem e retenção de água (PLATE-FORME POUR LE COMMERCE ÉQUITABLE, 2010).

Neste cenário, o presente estudo propõe-se a responder a seguinte questão de pesquisa: Quais ações vinculadas aos princípios do Comércio Justo podem contribuir para a mitigação dos efeitos nocivos das mudanças climáticas? Para tanto, o objetivo central foi evidenciar como o Comércio Justo, por meio das suas exigências e princípios, pode contribuir para diminuir os efeitos das mudanças climáticas. Em um primeiro momento, foi realizado um estudo exploratório com o emprego da técnica de análise documental, por meio da pesquisa de exemplos em que as boas práticas ambientais contribuíram para a manutenção do meio ambiente e da biodiversidade. Além disso, foi analisado o caso do algodão agroecológico, especificamente em três organizações pertencentes à cadeia produtiva deste tipo de algodão, cultivado no nordeste do Brasil e comercializado em outras regiões e países.

Apesar da recessão da economia mundial, a produção e o uso de algodão orgânico e ecológico pelas empresas continuam crescentes. Estas apresentam interesse e fazem investimentos em tecnologias para trabalhar com este algodão. Segundo a pesquisa da Organic Exchange, as vendas mundiais de algodão orgânico no varejo alcançaram o valor de U\$ 4,3 bilhões em 2009, representando um aumento de 35\% em relação a 2008 (ORGANIC EXCHANGE, 2010).

A Organic Exchange também listou as doze empresas que mais utilizaram o algodão orgânico no ano de 2009, apontando várias marcas conhecidas e de renome, destacando-se a C\&A ${ }^{\circledR}$, da Bélgica, a Nike ${ }^{\circledR}$ e a Walmart ${ }^{\circledR}$ dos Estados Unidos. De acordo com o relatório, o mercado desse tipo de algodão é crescente uma vez que as empresas estão mais preocupadas em saber a origem dos produtos, assim como diminuir a sua pegada de carbono (ORGANIC EXCHANGE, 2010). O algodão orgânico representa uma pequena parcela de todo 
o algodão produzido, em torno de $1 \%$ apenas. Porém, ao contrário da produção global do algodão convencional, o cultivo de orgânico apresenta índices crescentes, tanto que há cinco anos, a produção que atualmente é de pouco mais de 1\%, era de 0,1\% (TRUSCOTT et al., 2010; TEXTILE EXCHANGE, 2011).

Para a presente pesquisa, foram coletados dados junto a organizações de Comércio Justo no Brasil que trabalham com o algodão orgânico, e que promovem desenvolvimento territorial com apropriação das comunidades locais por meio da agricultura, tendo em vista que a cadeia do algodão agroecológico apresenta robustos elementos para a análise. Destaca-se ainda a importância desse estudo, uma vez que a produção de orgânicos é crescente e apresenta uma interface com o Comércio Justo. O avanço nesse tipo de estudo, que faz a conexão entre os temas Comércio Justo, orgânicos e mudanças climáticas pode trazer contribuições para a preservação do meio ambiente, estimular projetos de empreendedorismo e inovação social, além de incentivar políticas públicas.

Assim, o trabalho está estruturado da seguinte forma: a segunda seção apresenta alguns aspectos sobre mudanças climáticas, seguida da revisão de literatura sobre o Comércio Justo. Na quarta seção são apresentados exemplos que abordam de que maneira o Comércio Justo pode atuar como agente mitigador das mudanças climáticas. Na sequência são descritos os procedimentos metodológicos, enquanto a sexta seção contempla a análise das associações estudadas nesta investigação. Por fim, apresentam-se as considerações finais.

\section{Mudanças Climáticas}

Segundo o relatório do Intergovernmental Panel on Climate Change (IPCC, 2007), a produção mundial de alimentos pode sofrer um impacto nos próximos anos devido às mudanças climáticas provocadas pelo aquecimento global. Este documento aponta que a elevação da temperatura ameaça o cultivo de várias espécies agrícolas e poderá contribuir para aprofundar o não menos grave problema da fome em algumas áreas do planeta. Nações pobres da África e da Ásia devem ser as mais atingidas, mas grandes produtores agrícolas, como o Brasil, tendem a sofrer os mesmos efeitos em um curto prazo.

Para Assad e Pinto (2008), as atividades agropecuárias têm uma relação de causa e efeito com a elevação da temperatura terrestre. A agricultura e a pecuária são duas das vítimas deste cenário, mas também foram responsáveis pela sua intensidade nas últimas décadas devido à forma como esta atividade foi praticada. Helm (2008) defende que até o momento pouco se fez para mitigar as mudanças climáticas, e afirma que se deve aprofundar estudos a respeito dos impactos das alterações climáticas sobre o crescimento econômico, envolvendo os custos de mitigação e considerando a necessidade de aproximar a ciência dos setores de política global.

Neste cenário, pode-se dizer que o pequeno produtor rural brasileiro já sofre os efeitos das variações climáticas. Talvez por essa razão tenha sido criado, em agosto de 2010, o Fundo Nacional de Mudanças Climáticas no Brasil. São R \$ 200 milhões para investimento em ações de mitigação e adaptação aos efeitos das mudanças do clima no país (AMÉRICO, 2010). Com o aquecimento global, a cultura do algodão é uma das que poderá sofrer uma redução de áreas de plantio de baixo risco, em especial na região Nordeste. Assim, estima-se um impacto negativo de R\$ 312 milhões, em 2020, somente para esse tipo de planta (ASSAD; PINTO, 2008).

No entanto, técnicas como a do plantio direto (em que há o cultivo sobre a palha deixada no solo pela cultura anterior sem a necessidade de sua remoção) e a não utilização de produtos agroquímicos podem promover um uso mais consciente da terra, diminuindo as emissões e ainda sequestrando o carbono da atmosfera (ASSAD; PINTO, 2008). Destaca-se que o uso de técnicas de cultivo que respeitem o meio ambiente, como a agroecologia, são fundamentais para essas reduções.

Os fertilizantes sintéticos à base de nitrogênio, usados na agricultura tradicional, são os maiores contribuintes para emissões de um gás de efeito estufa denominado de óxido nitroso (N2O). Este gás é 300 vezes mais potente que o dióxido de carbono (CO2), trazendo consequências nefastas para o aquecimento 
global (TEXTILE EXCHANGE, 2012). Ressalta-se que neste estudo considera-se agricultura tradicional ou convencional, aquela praticada mediante o emprego de herbicidas, inseticidas, desfolhantes, fertilizantes, entre outros, oriundos de produtos sintéticos ou agroquímicos.

Por sua vez, a agricultura orgânica, especialmente quando realizada com plantio direto, responde e mitiga a mudança climática, reduzindo os requisitos de energia para os sistemas de produção de 25 a 50\% em comparação com a agricultura de base química convencional. Evita-se o uso de fertilizantes, minimizando a emissão de N2O e aumentando os teores de matéria orgânica. Além disso, a agricultura orgânica, comparativamente à agricultura convencional, apresenta maior resistência a condições climáticas extremas, como secas e inundações (TEXTILE EXCHANGE, 2012).

Como será detalhado na próxima seção, a proteção do meio ambiente e os incentivos ao desenvolvimento de técnicas de produção e cultivo que sejam compatíveis com a manutenção de uma agricultura sustentável, estão entre os princípios do Comércio Justo.

\section{Comércio Justo}

O Comércio Justo é uma abordagem alternativa ao comércio tradicional e é baseado na parceria comercial entre produtores e consumidores, onde os primeiros têm melhores condições comerciais e os últimos, por meio de suas compras diárias, encontram um meio de ajudar a reduzir a pobreza (FLO, 2011). Comércio Justo pode ser definido como uma associação comercial orientada para o desenvolvimento sustentável e para os produtores excluídos ou em desvantagem. São oferecidas melhores condições comerciais, nas quais se paga um preço justo para os produtores, fortalecendo-os e proporcionando-lhes maior autonomia (FRETEL; SIMONCELLI-BOURQUE, 2003; FLO, 2011b).

O Comércio Justo começou por iniciativa cristã no hemisfério Norte nos anos 1940 e 1950 e se alastrou para todo o mundo, passando a ser difundido também para a comercialização (não só produção) nos países em desenvolvimento, como é o caso do Brasil. Nessa evolução, nos anos 1950 e 1960 as Organizações Não Governamentais (ONGs) cristãs desenvolveram as
Alternative Trade Organizations (ATOs) iniciando a importação e venda de artesanato do Comércio Justo através de solicitação por correio e grupos de solidariedade da Igreja (FRIDELL, 2004; DORAN; NATALE, 2010). Os anos 1970 e 1980 foram marcados pelo crescimento das redes de Comércio Justo. E, na busca de uma maior legitimidade, nos anos 1980 ocorre a inserção nos mercados tradicionais e surge a necessidade de uma normatização.

Dessa forma, em 1988, surgiu a certificação de Comércio Justo na Holanda. Nesta primeira iniciativa, a ideia era de certificar e comprar, a um preço relativamente mais alto do que o praticado pelo mercado, produtos de pequenos produtores que, em contrapartida, deveriam respeitar o meio ambiente e utilizar critérios democráticos e solidários nas suas relações (FRETEL; SIMONCELLIBOURQUE, 2003).

Posteriormente, o conceito foi ampliado para incluir o reconhecimento e a valorização do trabalho e das expectativas dos produtores e consumidores. Inclui-se, dessa maneira, a preocupação com qualidade de vida das pessoas, tornando viável a vigência dos direitos humanos e o respeito ao meio ambiente numa perspectiva de desenvolvimento humano, solidário e sustentável. As técnicas de produção devem ser favoráveis às questões ambientais e a organização da produção deve ser democraticamente administrada (FRETEL; SIMONCELLI-BOURQUE, 2003; McMURTRY, 2009).

Assim, destaca-se que a prática e a teoria do Comércio Justo devem conter não só os elementos que evidenciam os impactos econômicos e humanos para o desenvolvimento, mas também sua capacidade de fundamentar a sua pretensão de prestação de justiça através do mercado (McMURTRY, 2009). Para os produtores, o Comércio Justo é único por oferecer quatro importantes benefícios: i) preços estáveis - o valor pago cobre pelo menos os custos da produção sustentável, mesmo quando os preços do mercado mundial caem; ii) o prêmio pago pelos produtos do Comércio Justo ajuda os produtores a melhorarem a sua vida e a de suas famílias; iii) parcerias - produtores envolvidos nas decisões que afetam o seu futuro; iv) empoderamento dos trabalhadores - este é 
um objetivo do Comércio Justo. Dessa forma, grupos de pequenos produtores devem ter uma estrutura democrática e uma administração transparente para serem certificados (FLO, 2010).

Observa-se que os objetivos do Comércio Justo incluem melhorar as condições e o bem estar de produtores por meio de um maior acesso aos mercados e de um reforço às organizações destes trabalhadores. A proposta é pagar preços adequados e promover uma continuidade nas relações de comércio, promovendo oportunidades de desenvolvimento para produtores e grupos desfavorecidos, como mulheres e índios. Outro ponto de destaque é a importância da conscientização dos consumidores para que exerçam seu poder de compra de uma forma positiva (CLARKE et al., 2007).

Conforme mencionado, o preço pago pelo Comércio Justo envolve todo o valor do trabalho empregado, sem que este seja subvalorizado, como muitas vezes acontece no comércio tradicional. Além disso, ainda é pago uma quantia a mais, chamada de prêmio de Comércio Justo. Esse dinheiro é direcionado para um fundo comum do grupo de produção para melhorar as suas condições sociais, econômicas e do meio ambiente. Como toda a gestão de Comércio Justo se caracteriza pela transparência, o uso desse valor deve ser decidido de forma democrática, geralmente por meio de assembleias. $\mathrm{O}$ investimento pode ser feito em educação, saúde e aprimoramento dos meios de produção para agregar mais qualidade e valor aos produtos (FLO, 2010).

Assim, o que distingue os produtos do Comércio Justo não é a particularidade ou singularidade dos produtos em si, ou a campanha de marketing, mas sim a proposta de que o consumo desses bens contribui para o desenvolvimento ético local. Além disso, este tipo de comércio recompensa e encoraja práticas agrícolas e de produção que sejam ambientalmente sustentáveis, como, por exemplo, a produção orgânica. Desse modo, fica clara a existência de uma simbiose entre os movimentos, onde, a adoção da produção e certificação orgânica encontra um significativo estímulo do Comércio Justo, especialmente para produtos como café, chocolate e chá (FLO, 2010; McMURTRY, 2009).
Nota-se que a importância da certificação aparece fortemente na cadeia de agroalimentos, cuja valorização e reconhecimento da qualidade dentro do mercado são alcançados pelo próprio processo de certificação. A qualidade dos alimentos não é relacionada somente às suas propriedades físicas, mas também às questões intangíveis, como os aspectos sociais incorporados ao produto, que podem inclusive ampliar o seu valor econômico (DE PELSMACKER; JANSSENS, 2007; RENARD, 2005).

Esse processo de certificação requer que uma organização regulatória, pública ou privada, determine os critérios de qualidade legítimos. Essa organização pode ter uma função econômica (barreira à entrada de novos concorrentes e processos de cooperação econômica entre os atores), funções jurídicas (por proteger a renda de diferenciação) e funções institucionais (RENARD, 2005).

Dessa forma, de acordo com a FLO (2010), os produtores têm uma série de responsabilidades com relação ao incremento dos modos de produção sustentáveis. Eles devem desenvolver um plano para diminuir seus impactos e realizar um monitoramento contínuo para observar os resultados. Os produtores, dentro do conceito de Comércio Justo, devem: i) proteger o meio onde trabalham e vivem, incluindo a água, florestas virgens e outras importantes áreas de terras, lidando com os problemas de erosão e gestão de resíduos; ii) desenvolver, implementar e monitorar planos de operação nas suas técnicas agrícolas. Estas devem incluir o equilíbrio entre a proteção ao meio ambiente e bons resultados nos negócios; iii) seguir padrões nacionais e internacionais para manejar produtos químicos. Há uma lista de produtos que não podem ser utilizados; iv) não utilizar, intencionalmente, produtos genericamente modificados; v) planejar e monitorar que efeitos suas atividades estão causando no ambiente (FLO, 2010).

Alguns exemplos de adoção da certificação de Comércio Justo demonstram a sua contribuição para promover as práticas respeitosas ao meio ambiente. Segundo Zarioh (2007), a organização dominicana Banelino, composta por produtores de banana, utiliza o prêmio de Comércio Justo exigido pela certificadora 
para financiar ações ambientais. Financiam sessões de formação e educação sobre meio ambiente para diversos públicos - produtores, assalariados, fazendeiros, alunos e grupos comunitários. Ainda utilizam parte do prêmio para: i) ações de mitigação da destruição da biodiversidade atenuação das pulverizações químicas aéreas e introdução de espécies vegetais que possam agir para isso; ii) facilitar a fertilização do solo; e, iii) reduzir a utilização de água - através da cobertura vegetal e de sistemas de irrigação (ZARIOH, 2007).

Em seu estudo, Zarioh (2007) também menciona que, além desse efeito, o produtor vinculado à organização Banelino compreende as vantagens que ele procura para a sua família e para os assalariados agrícolas que emprega. Percebe que o retorno da venda de Comércio Justo melhora a segurança de sua casa e vincula o apoio à produção (por meio de um enquadramento técnico e da facilidade de financiamento dos insumos), aos maiores ganhos de produtividade e de rendimentos. O produtor considera que o acesso à inovação técnica e os investimentos produtivos permitidos pelo prêmio de desenvolvimento são necessários para ser mais competitivo no mercado de banana, que, em geral, é dominado por grandes plantações (ZARIOH, 2007).

Pode-se perceber que o Comércio Justo tem um forte apelo para o desenvolvimento sustentável. Há preocupação com os ganhos econômicos para os produtores, que recebem um prêmio, com vistas a melhorar a sua qualidade de vida, de sua família, assim como do ambiente onde vivem. Isto é, contempla os pilares econômico, social e ambiental preconizados no desenvolvimento sustentável. Dessa forma, nesta seção, abordou-se de maneira ampla os objetivos e ações relacionados às práticas de Comércio Justo. A seguir, são apresentados a reflexão teórica e uma série de exemplos relatados na literatura sobre as práticas de Comércio Justo que contribuem para a mitigação dos efeitos das mudanças climáticas, foco deste estudo.

\section{Comércio Justo Como Agente Mitigador Das Mudanças Climáticas}

O Comércio Justo encoraja os modos de produção sustentáveis, inserido na perspectiva de desenvolvimento territorial com apropriação das comunidades locais por meio da agricultura orgânica, de florestas sustentáveis, da rotação de culturas, da integração da agricultura e pecuária e de técnicas de estocagem e retenção de água (PLATE-FORME POUR LE COMMERCE ÉQUITABLE, 2010). Ou seja, o Comércio Justo critica a produção, comercialização e relações de consumo convencionais, buscando uma nova maneira de produzir, combinando objetivos que visam a justiça social com o engajamento na economia global, podendo até mesmo ser interpretado como um contra-movimento (RAYNOLDS, 2002; RAYNOLDS, 2012).

O movimento orgânico internacional centra-se na reincorporação de “processos naturais", incentivando o comércio de produtos agrícolas produzidos sob condições orgânicas certificadas e bens processados derivados dessas mercadorias. Nota-se que o poder normativo do Comércio Justo deriva de sua capacidade de passar de uma visão crítica a uma positiva, que intercala valores sociais/ecológicos e direitos e responsabilidades pessoais/ globais (RAYNOLDS, 2000).

Para as organizações de Comércio Justo, uma resposta eficaz às mudanças climáticas deve promover e se apoiar em todas as dimensões do desenvolvimento sustentável: proteção ao meio ambiente, economia justa, justiça social, diversidade cultural e participação dos atores. O Comércio Justo contribui de diferentes maneiras na prevenção dos desequilíbrios climáticos e para a adaptação aos seus efeitos. Suas iniciativas apóiam os produtores do hemisfério Sul, que privilegiam os modos de produção agrícola e artesanal, com pouca emissão de carbono e permitindo a correção do solo e das florestas. Por sua vez, a estabilidade de preços e a segurança alimentar permitem às cooperativas uma autonomia e investimentos em bens sociais, como saúde e educação (PLATE-FORME POUR LE COMMERCE ÉQUITABLE, 2010).

Nesse cenário, os atores do Comércio Justo se mobilizam para atenuar os efeitos do desregramento do clima sobre os pequenos produtores, apoiando a agricultura, sobretudo nos países em desenvolvimento. 
Dessa forma, o Comércio Justo contribui para limitar a emissão de gases poluentes e incentivar os compromissos econômicos, sociais e ambientais perante as práticas agrícolas que garantem a proteção do meio ambiente e a manutenção das condições razoáveis de remuneração para os pequenos produtores (PLATE-FORME POUR LE COMMERCE ÉQUITABLE, 2010).

Os membros da Plate-forme Pour le Commerce Équitable (2010) e seus parceiros defendem um consumo menor de recursos naturais e demais insumos, utilização de materiais naturais ou reciclados, promoção de um novo comportamento de consumo, diminuição das embalagens e priorizar o transporte por navios. No Quadro 1, aparecem os setores identificados como os mais emissores de gases de efeito estufa e as respostas do Comércio Justo.

Quadro 1 - Respostas do Comércio Justo aos setores mais emissores de gases de efeito estufa

\begin{tabular}{|l|l|}
\hline \multicolumn{1}{|c|}{ Setor } & \multicolumn{1}{c}{ Resposta do Comércio Justo } \\
\hline $\begin{array}{l}\text { Fornecimento de Energia } \\
\text { Elétrica }\end{array}$ & Escolher fornecedores de energia verde e renovável \\
\hline Indústria & $\begin{array}{l}\text { Comercializar produtos artesanais e uso de recicláveis com a } \\
\text { mínima utilização de recursos }\end{array}$ \\
\hline Transporte & Priorizar o transporte por navio e o comércio local \\
\hline Desflorestamento & $\begin{array}{l}\text { Ajudar as comunidades a preservar as florestas fornecendo } \\
\text { uma saída para a comercialização de seus produtos }\end{array}$ \\
\hline Agricultura & Apoio à pequena agricultura orgânica e sustentável \\
\hline
\end{tabular}

Fonte: Plate-forme Pour le Commerce Équitable (2010).

No setor de agricultura, por exemplo, a cooperativa Organic Rice Fund Surin Agriculture Cooperative (ORFSC) é produtora de arroz, uma planta muito sensível à mudança de temperatura e que consome considerável volume de água. É certificada pelo Comércio Justo por outra cooperativa, a Green Net. A ORFSC encontrou nas práticas orgânicas, um meio de se adaptar ao ambiente afetado pelas mudanças climáticas. Entre as ações desenvolvidas, destacam-se: i) selecionam variedades que consomem menos água, como a espécie jasmine; ii) foram desenvolvidos sistemas de cultura agroecológicos: construção de barragens para irrigar os arrozais, realizam compostagem, plantam algumas leguminosas alternadamente com o arroz, fazem o combate orgânico aos insetos, providenciam plantações de árvores frutíferas e trabalham com piscicultura (LE LABORATOIRE DU COMMERCE EQUITABLE, 2008).

O estudo realizado por Nelson et al. (2010) identificou algumas dimensões que podem ser trabalhadas no contexto do Comércio Justo para ajudar no combate e na adaptação às alterações provocadas pelas mudanças climáticas. São ações que podem ser feitas no campo e que vão auxiliar no fortalecimento do Comércio Justo, na agregação de valor aos produtos e maior desenvolvimento para os produtores rurais. As dimensões propostas no estudo são as de adaptação humana, ecológica, econômica, social, física e política, de acordo com a Figura 1.

Figura 1 - Dimensões para a adaptação às mudanças climáticas: sugestões de ações para grupos de Comércio Justo

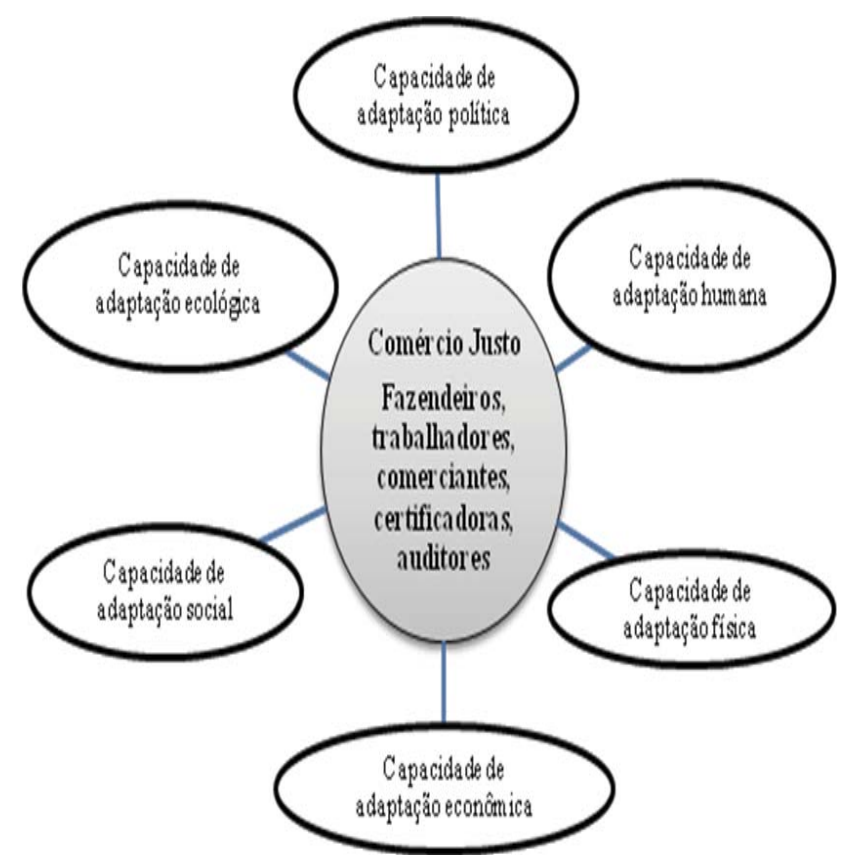

Fonte: Adaptado de Nelson et al. (2010).

Para cada uma dessas dimensões, os autores propõem ações que podem ser tomadas pelos atores do Comércio Justo, conforme o Quadro 2. 
Quadro 2 - Dimensões e práticas do Comércio Justo para o novo cenário das mudanças climáticas.

\begin{tabular}{|c|c|}
\hline Dimensões & Ações Práticas \\
\hline $\begin{array}{l}\text { Capacidade de } \\
\text { adaptação } \\
\text { humana }\end{array}$ & $\begin{array}{l}\text { Continuação e incremento dos prêmios para o desenvolvimento das comunidades } \\
\text { (projetos de educação, saúde e meio ambiente). Educar consumidores sobre mudanças } \\
\text { climáticas e desenvolvimento. Encorajar a educação em casos de desastres naturais } \\
\text { causados pelas mudanças climáticas. }\end{array}$ \\
\hline $\begin{array}{l}\text { Capacidade de } \\
\text { adaptação } \\
\text { ecológica }\end{array}$ & $\begin{array}{l}\text { - Manter e aumentar o acesso aos principais recursos naturais, como fontes de água, } \\
\text { terra produtiva, além de melhorar a gestão dos recursos naturais. Importância do } \\
\text { monitoramento; } \\
\text { - Apoiar a agroecologia, métodos de produção amigáveis ao meio ambiente, que } \\
\text { maximizem a agrobiodiversidade; } \\
\text { - Apoiar a aprendizagem e as trocas entre os produtores de Comércio Justo e as } \\
\text { comunidades para as estratégias adaptativas, além de identificar tecnologias que } \\
\text { promovam a mitigação e adaptação; Procurar fundos para apoiar o uso de tecnologias } \\
\text { para incrementar os métodos agrícolas. }\end{array}$ \\
\hline $\begin{array}{l}\text { Capacidade de } \\
\text { adaptação } \\
\text { econômica }\end{array}$ & $\begin{array}{l}\text { Aumentar a renda e a diversidade das fontes de renda: apoiar a policultura; } \\
\text { - Considerar como o preço do Comércio Justo pode refletir as mudanças nos custos } \\
\text { de produção impostos pelas mudanças climáticas; } \\
\text { - Coletar dados mais precisos para previsão da demanda; } \\
\text { - Monitorar como as mudanças climáticas e outros fatores afetam os mercados e o } \\
\text { comércio das commodities de Comércio Justo e quais são os impactos econômicos para } \\
\text { as famílias mais pobres; } \\
\text { - Nas avaliações de impacto, levar em conta a diversificação nas fontes de renda e na } \\
\text { construção de ativos, considerando também a cultura de alimentos versus a cultura de } \\
\text { rendimento; } \\
\text { - Buscar oportunidades para agregação de valor dos produtos; } \\
\text { - Explorar o potencial de colaboração com os padrões ambientais e de certificação; } \\
\text { - Inovar através de parcerias na cadeia de valor para obter os investimentos e } \\
\text { também para ajudar a manter ou garantir o acesso ao mercado. }\end{array}$ \\
\hline $\begin{array}{l}\text { Capa } \\
\text { adapta }\end{array}$ & $\begin{array}{l}\text { Apoiar a organização democrática dos produtores e trabalhadores para construir as } \\
\text { bases da ação coletiva para a adaptação às mudanças devido a alterações no clima; } \\
\text { - Compreender melhor como as famílias rurais recorrem formal e informalmente } \\
\text { aos recursos sociais e às redes para a sua subsistência, especialmente em tempos } \\
\text { difíceis; } \\
\text { - Continuar a reforçar as redes de Comércio Justo e o seu conhecimento do clima, } \\
\text { incentivando o seu engajamento na defesa e em torno de processos de adaptação ao } \\
\text { clima; } \\
\text { - Criar parcerias com universidades e pesquisadores sobre o tema; } \\
\text { - Incentivar o conhecimento para técnicas de agricultura adaptativas: estimular ações } \\
\text { que levem conhecimento sobre as mudanças climáticas aos trabalhadores do campo } \\
\text { (tecnologia de informação em celulares, notebooks, internet); } \\
\text { Incluir as mudanças climáticas nas avaliações e planejamentos organizacionais dos } \\
\text { grupos de Comércio Justo; Fazer trabalhos de educação com os consumidores sobre os } \\
\text { custos humanos das mudanças climáticas; Reduzir queimadas e introduzir mais } \\
\text { questões relacionadas à proteção do meio ambiente nas auditorias de Comércio Justo. }\end{array}$ \\
\hline $\begin{array}{l}\text { Capacida } \\
\text { adaptação }\end{array}$ & $\begin{array}{l}\text { Melhorar infraestrutura através dos prêmios; } \\
\text { - Fazer as adaptações físicas de design de plantação e localização para melhor } \\
\text { aproveitamento dos recursos; } \\
\text { - Construir o conhecimento acerca do tema. }\end{array}$ \\
\hline $\begin{array}{c}\text { Capacidade de } \\
\text { adaptação } \\
\text { política }\end{array}$ & $\begin{array}{l}\text { Incluir o agricultor nas discussões nacionais e internacionais sobre a temática; } \\
\text { Trabalhar com esses produtores para que sejam representantes políticos do } \\
\text { Comércio Justo; } \\
\text { - Aumentar a participação de mulheres e outros grupos em desvantagem como vozes } \\
\text { ativas na tomada de decisão; } \\
\text { - Utilização de plataformas de aprendizagem e comunicação para a troca de ideias } \\
\text { entre os grupos. }\end{array}$ \\
\hline
\end{tabular}
Fonte: Adaptado de Nelson et al. (2010).

De acordo com a Figura 1 e o Quadro 2, Nelson et al. (2010) apresentam as medidas que podem ser tomadas pelos grupos de produção certificados pelo Comércio Justo. O Comércio Justo deve procurar construir a capacidade de adaptação e resiliência dos agricultores e trabalhadores para que possam se preparar e responder à variabilidade de mudanças climáticas. Pode-se observar que várias medidas ao longo das dimensões estão sobrepostas ou inter-relacionadas (NELSON et al., 2010).

Com o intuito de identificar como as práticas do Co- 
Comércio Justo podem contribuir para a mitigação dos efeitos nocivos das mudanças climáticas, apresentam-se dados de associações de Comércio Justo vinculadas à produção do algodão agroecológico. Destas instituições, foram coletadas as informações que são relevantes para o estudo proposto, ou seja, as que se relacionam com as consequências das atividades de produção e consumo no meio ambiente.

\section{Procedimentos Metodológicos}

Este estudo possui caráter estritamente qualitativo. Segundo Vieira (2006, p. 18), uma importante "característica da pesquisa qualitativa é que ela geralmente oferece descrições ricas e bem fundamentadas, além de explicações sobre processos em contextos locais identificáveis", em conformidade com a presente proposta. A investigação foi conduzida em duas etapas, uma exploratória e outra descritiva.

a) Etapa exploratória: visando obter subsídios para a análise da etapa descritiva foi realizada uma revisão da literatura, em busca de modelos já existentes que contemplam as práticas de Comércio Justo na mitigação dos efeitos nocivos das mudanças climáticas;

b) Etapa descritiva: a partir de dados primários e secundários, estudou-se o caso do algodão agroecológico, especificamente em três organizações pertencentes à cadeia produtiva deste tipo de algodão: a Associação de Desenvolvimento Educacional e Cultural de Tauá (ADEC), responsável pela produção, no nordeste do Brasil; a Tênis e a Justa Trama que comercializam o produto e possuem o certificado de algodão orgânico e do Comércio Justo.

A cadeia do algodão agroecológico estudada nesse trabalho inicia no interior do Ceará, Estado da região Nordeste do Brasil, onde os agricultores fazem o plantio e a colheita. São empregadas técnicas de conservação do solo e da água, valorizando a biodiversidade, sem o uso de agrotóxicos. Com relação a isso, os agricultores devem intercalar o cultivo de outras culturas secundárias, sempre sem o uso de agrotóxicos e, como consequência, há expansão da agricultura orgânica. Do total de algodão produzido, uma parte é vendida para a Rede Justa Trama e outra para a organização francesa Tênis.
A coleta de dados, na etapa descritiva, deu-se por meio de consultas a materiais das organizações ADEC, Tênis e Justa Trama, como sites, blogs, manuais e estatuto. Adicionalmente, foram feitas visitas e entrevistas nas duas últimas organizações, a partir de um roteiro previamente estruturado com base na primeira etapa deste estudo, contendo essencialmente questionamentos relacionados à comercialização dos produtos da cadeia (produção e transporte) e sobre a relação entre produtores, comerciantes e consumidores.

Entre os meses de dezembro de 2009 e novembro de 2010 realizaram-se as visitas e as entrevistas, que tiveram duração de 25 minutos a 2 horas. Estas foram gravadas e transcritas para a descrição dos resultados. Na Justa Trama, cuja sede está localizada na cidade de Porto Alegre - RS, foram realizadas duas visitas e uma entrevista com a presidente desta Rede. Por sua vez, na Tênis visitou-se o escritório localizado na cidade de Campo Bom - RS, onde entrevistou-se o sócio e gerente desta organização no Brasil. Na próxima seção são descritas as organizações estudadas e analisados os dados coletados.

\section{Resultados}

Nesta seção são apresentadas e discutidas as ações identificadas junto à cadeia produtiva e de comércio do algodão agroecológico, vinculadas aos princípios do Comércio Justo e capazes de contribuir para a mitigação dos efeitos nocivos das mudanças climáticas. Nas organizações estudadas foram identificadas as práticas segundo a Plate forme pour le commerce équitable, assim como as diretrizes sugeridas pelo estudo de Nelson et al. (2010).

A plataforma em prol do Comércio Justo (Plate forme pour le commerce équitable) é uma organização sem fins lucrativos, que tem como objetivo principal promover o Comércio Justo na França. É membro da organização mundial do Comércio Justo (do inglês WFTO - World Fair Trade Organization) e tem como associados diversas organizações que comercializam produtos com a certificação de Comércio Justo naquele país.

Os resultados estão organizados da seguinte forma: primeiramente apresentam-se características e 
peculiaridades da produção do algodão agroecológico. Posteriormente, tem-se a descrição e análise das três organizações investigadas, em conformidade com o objetivo proposto neste trabalho.

\subsection{Algodão Agroecológico}

O algodão orgânico é produzido atualmente em 23 países, sendo que as práticas de agricultura orgânica podem variar de um país para o outro. Mesmo assim, algumas práticas são comuns a todos: é proibido o uso de agroquímicos, como pesticidas, herbicidas e fertilizantes, além da proibição do uso de sementes geneticamente modificadas. O cultivo do algodão orgânico geralmente faz parte de um sistema de produção que protege o solo, a biodiversidade e as pessoas envolvidas. O objetivo é trazer benefícios ao meio ambiente, promover relações justas entre as pessoas e uma boa qualidade de vida para todos os envolvidos (IFOAM, 2011; TEXTILE EXCHANGE, 2011).

A qualidade do algodão orgânico varia na mesma extensão que a do algodão convencional. Diferentes qualidades terão diferentes preços, a qualidade da fibra do algodão é determinada por três fatores: a cor da fibra, a pureza e a qualidade do processo de descaroçamento (separação da fibra da semente) e o comprimento da fibra. Sua qualidade depende também do tipo de algodão, das condições de crescimento, das variáveis ambientais e climáticas e da expertise dos produtores, ou seja, depende das condições de colheita, armazenamento e beneficiamento (TAVARES et al., 2010; TEXTILE EXCHANGE, 2011).

A temperatura do solo é uma importante variável para o crescimento e desenvolvimento das plantas. De acordo com Nabi e Mullins (2008), as raízes de algodão cultivadas em temperatura muito baixa ou alta, apresentam distúrbios de crescimento. No experimento dos autores, a temperatura que provê o melhor crescimento da planta é $32^{\circ} \mathrm{C}$. As demais experiências, com 20 e 38 graus, geraram plantas menores. No próximo item, analisase a ADEC, associação que reúne os produtores de algodão agroecológico no Ceará, à luz das abordagens já mencionadas.

\subsection{Organizações InVESTIGADAS}

Conforme mencionado, este trabalho envolveu uma organização produtora de algodão agroecológico e outras duas que o comercializam, apresentadas e discutidas a seguir.

a) Associação de Desenvolvimento Educacional e Cultural de Tauá (ADEC)

Situada no nordeste brasileiro, na cidade de Tauá, a Associação de Desenvolvimento Educacional e Cultural de Tauá (ADEC) é a entidade de produtores que, desde 1993, cultiva o algodão agroecológico, que é beneficiado na própria Associação. São 320 famílias que vivem desta agricultura agroecológica. Em 2003, iniciou a comercialização de sua produção para duas cadeias produtivas do Comércio Justo. Uma parte é vendida à Tênis, uma empresa francesa e a outra parte é vendida para a Rede Justa Trama, que articula uma rede de cooperativas em todo o Brasil para produção de confecções. Organizados em associação, a negociação é feita de forma direta entre a Tênis, a Justa Trama e a ADEC, sendo estabelecida uma relação mais humana, com redução dos intermediários, fazendo com que a remuneração dos produtores seja maior.

O nordeste do Brasil apresenta vantagens comparativas em relação a outras regiões produtoras, pois, historicamente, sempre empregava volumes reduzidos de agrotóxicos, o que facilita a conversão às práticas agroecológicas por um número expressivo de agricultores familiares (LIMA; SOUZA, 2006). Em geral, um produtor membro da ADEC possui uma propriedade com mais ou menos um hectare e produz 150 kg de algodão por ano. O preço do algodão em pluma é fixado em parceria com as famílias, 2,35 EUR/Kg, que é o dobro do preço de mercado. Este preço cobre os custos de produção do algodão agroecológico e permite aos produtores um retorno razoável (TÊNIS, 2010).

O Estado do Ceará, onde é plantado o algodão agroecológico, é marcado por um solo frágil e poucas chuvas. A ADEC investe na produção sustentável de produtos ecologicamente corretos, oriundos da agricultura familiar, com certificação orgânica concedida 
pelo Instituto Biodinâmico (IBD) e certificação de Comércio Justo pela Fair Trade International - FLO Fair Trade. Longe das monoculturas e explorações agrícolas convencionais, o algodão e as culturas de subsistência são plantados em um mesmo campo, sem adubo ou pesticidas, de acordo com os princípios da agroecologia.

A certificação de Comércio Justo para o algodão influencia nas melhores condições de trabalho e econômicas para os produtores da planta. Porém, não interfere no processo de manufatura para o produto final. Os padrões e princípios do Comércio Justo determinam que todas as organizações envolvidas devem também oferecer garantias de que estão proporcionando boas condições para os trabalhadores (FAIR TRADE FOUNDATION, 2010).

Umprêmio deComércio Justoédestinadoà associação ADEC no fim da colheita que é usado coletivamente para melhorar a terra e a vida dos agricultores. Entre 2007 e 2009, serviu para pagar as certificações orgânica e do Comércio Justo. Além disso, a Tênis, por exemplo, estabelece contratos de compra de três anos, o que faz com que os agricultores já saibam o preço dos produtos antes mesmo de plantá-los.

Por sua vez, a ONG brasileira Esplar, situada em Fortaleza, no Ceará, auxilia os produtores da ADEC na sua organização e através do suporte técnico de seus engenheiros agrônomos. Eles introduziram o uso da árvore Neem para proteger as colheitas. O óleo extraído dessa árvore age como um repulsivo natural contra os insetos. Além disso, implantaram a policultura, que oferece uma independência alimentar e preservação do equilíbrio das terras cultivadas. O algodão é integrado à cultura de milho, gergelim e feijão, que constituem a base alimentar dos produtores.

De acordo com o seu plano ambiental, a ADEC afirma a sua preocupação com a capacidade de adaptação ecológica ao adotar estratégias de cultivo do solo e técnicas agrícolas sustentáveis. Em seu processo produtivo, a organização não utiliza produtos químicos tóxicos que são potenciais contaminantes do solo, do ar (pulverizações) e da água de superfície e subterrânea, o que torna o agricultor um "vizinho mais responsável".
Tal fato contribui para que a plantação demande um menor volume de água, pois os solos orgânicos têm potencial para reter a umidade entre 30 e $50 \%$ a mais em comparação aos que recebem insumos sintéticos e não naturais (TEXTILE EXCHANGE, 2012).

Em 2010, o plano ambiental da ADEC foi dividido em sete partes: conservação do solo, plantio do algodão, manejo de insetos e pragas, preservação dos recursos genéticos e segurança alimentar, insumos naturais, descarte dos resíduos sólidos e desenvolvimento ambiental. Essas ações, apresentadas no Quadro 3, influenciam as demais dimensões indicadas por Nelson et al. (2010), uma vez que a adaptação ambiental inclui as dimensões sociais, humanas, físicas e assim por diante.

No Quadro 3, constata-se que as ações ambientais propostas pela ADEC para a produção de algodão orgânico contemplam as dimensões propostas por Nelson et al. (2010) para a mitigação dos efeitos das mudanças climáticas e para melhorar a capacidade de adaptação. Portanto, o Comércio Justo, juntamente com a produção orgânica, permitem uma forma de produção mais sustentável do que a feita de maneira tradicional, com o uso de técnicas mais agressivas ao meio ambiente, aos trabalhadores e também aos consumidores. O acesso a esse produto se dá por meio de organizações como a Tênis e a Rede Justa Trama, abordadas nos próximos itens.

\section{b) Organização Tênis}

A organização francesa, aqui denominada Tênis, produz bolsas e tênis exclusivamente com os princípios do Comércio Justo e usando como matéria-prima o algodão agroecológico, borracha natural e couro vegetal importados do Brasil. A iniciativa começou com uma pergunta emitida pelos seus fundadores: 'um outro mundo é possível?’. Com o algodão agroecológico do nordeste brasileiro, com a borracha silvestre da Amazônia e com o couro curtido com acácia, a Tênis tenta encontrar novas maneiras de trabalhar, e propõe uma nova forma de pensar e agir criando um canal solidário e ecológico do produtor ao consumidor (TÊNIS, 2010).

Os produtos da Tênis são fabricados no Vale dos Sinos (região metropolitana de Porto Alegre, no Rio 
Grande do Sul). As fábricas são terceirizadas, porém auditadas pelas organizações de Comércio Justo FLOCert e Ecolabel. A maioria dos empregados faz parte de uma comunidade de origem alemã e a fábrica respeita as regras da Organização Internacional do Trabalho (OIT). Ainda, para garantir que o trabalho seja exercido dentro dos princípios da dignidade, são seguidos alguns critérios: que trabalha na lógica da ecologia e da solidariedade. A lógica da ecologia é exercida por meio da utilização de fontes renováveis, como solar, eólica, hídrica e de biogás, para a geração de energia. A solidariedade é fruto da associação em forma de cooperativa, caracterizando a fornecedora de energia como uma empresa solidária (ENERCOOP, 2010). a proximidade das casas, nível de vida e poder de compra, vantagens sociais e liberdade de expressão aos empregados. Quarenta por cento dos trabalhadores vivem próximos da fábrica e os demais nas cidades vizinhas.

Ao invés de fazer apenas compensações, plantando árvores e “enterrando" carbono, a prioridade da Tênis é a redução das emissões. Existe a preocupação em mudar o modo de transporte, de organização da produção, de condicionamento e consumo. Todos os tênis e acessórios viajam de navio desde os arredores da cidade de Porto Alegre até Havre, na França. $O$ transporte continua em um outro tipo de barco até os arredores de Paris. As embalagens dos tênis são de papel reciclado e reciclável, as bolsas são acondicionadas Quadro 3 - Ações ambientais para o algodão orgânico

\begin{tabular}{|c|c|c|}
\hline $\begin{array}{l}\text { Plano Ambiental } \\
\text { ADEC } \\
\end{array}$ & Ações & Vantagens \\
\hline \multirow{5}{*}{ Conservação do Solo } & $\begin{array}{l}\text { Plantio Consorciado: plantar em uma mesma } \\
\text { área uma diversidade de culturas. }\end{array}$ & $\begin{array}{l}\text { Diminui o risco de perdas de } \\
\text { safra por falta ou excesso de } \\
\text { chuvas e o ataque de pragas. } \\
\text { Fortalece o solo. }\end{array}$ \\
\hline & $\begin{array}{l}\text { Curvas de nível: plantar seguindo linhas que } \\
\text { estão na mesma altura do terreno. }\end{array}$ & \multirow{3}{*}{$\begin{array}{l}\text { Evita a erosão provocada pela } \\
\text { água das chuvas. }\end{array}$} \\
\hline & $\begin{array}{l}\text { Valetas de retenção que são feitas seguindo as } \\
\text { curvas de nível. }\end{array}$ & \\
\hline & $\begin{array}{l}\text { Enleiramento com garranchos ou mureta de } \\
\text { pedras para proteger o sulco que é feito para } \\
\text { receber as sementes }\end{array}$ & \\
\hline & $\begin{array}{l}\text { Adubação orgânica com esterco de bovinos, } \\
\text { caprinos ou ovinos. }\end{array}$ & $\begin{array}{l}\text { Melhora a fertilidade do solo e } \\
\text { a nutrição das plantas. }\end{array}$ \\
\hline \multirow{4}{*}{ Plantio do Algodão } & $\begin{array}{l}\text { A escolha do local para o plantio deve levar } \\
\text { em conta a umidade e a plantação do algodão } \\
\text { deve ser feita nas primeiras chuvas ou no } \\
\text { seco, se possível. }\end{array}$ & $\begin{array}{l}\text { A umidade influencia no } \\
\text { aparecimento do bicudo (praga } \\
\text { do algodão). }\end{array}$ \\
\hline & $\begin{array}{l}\text { O preparo do solo não pode ser feito com } \\
\text { queimadas. Se forem derrubadas árvores, } \\
\text { deve-se aproveitar a madeira. }\end{array}$ & $\begin{array}{l}\text { Evitar queimadas e a } \\
\text { decomposição inadequada da } \\
\text { madeira com emissão de } \\
\text { poluentes. }\end{array}$ \\
\hline & $\begin{array}{l}\text { Não utilizar sementes com tratamento } \\
\text { químico e priorizar o plantio das sementes de } \\
\text { variedades nativas. }\end{array}$ & Evitar a contaminação do solo. \\
\hline & $\begin{array}{l}\text { O roçado agroecológico deverá ter no mínimo } \\
\text { três culturas principais. O plantio do algodão } \\
\text { deve ser feito em faixas de } 4 \text { a } 6 \text { fileiras, } \\
\text { alternando com as demais culturas. }\end{array}$ & $\begin{array}{l}\text { Promove a diversidade de } \\
\text { culturas e de fontes de renda. }\end{array}$ \\
\hline \multirow{2}{*}{$\begin{array}{l}\text { Manejo de Insetos e } \\
\text { Pragas }\end{array}$} & $\begin{array}{l}\text { Evitar botões florais no chão. Fazer a limpeza } \\
\text { de duas a três vezes por semana. } \\
\end{array}$ & $\begin{array}{l}\text { Diminui o aparecimento do } \\
\text { bicudo. }\end{array}$ \\
\hline & $\begin{array}{l}\text { Uso de defensivos naturais contra as pragas e } \\
\text { uso de biofertilizantes. }\end{array}$ & $\begin{array}{l}\text { Combater as pragas sem o uso } \\
\text { de agroquímicos. }\end{array}$ \\
\hline $\begin{array}{c}\text { Preservação dos } \\
\text { recursos genéticos e } \\
\text { segurança alimentar }\end{array}$ & $\begin{array}{l}\text { Revitalização das Casas de Sementes da } \\
\text { ADEC e implantação de campos de produção } \\
\text { de orgânicos. }\end{array}$ & $\begin{array}{l}\text { Evitar o uso de transgênicos e } \\
\text { ter a garantia das sementes de } \\
\text { variedades nativas ou crioulas. }\end{array}$ \\
\hline Insumos naturais & Uso de biofertilizantes e defensivos naturais. & $\begin{array}{l}\text { Proteção natural das plantas } \\
\text { contra as pragas e doenças. }\end{array}$ \\
\hline Descarte & Destino adequado para os resíduos sólidos. & $\begin{array}{l}\text { Evitar a contaminação do meio } \\
\text { ambiente. }\end{array}$ \\
\hline \multirow[t]{2}{*}{$\begin{array}{l}\text { Desenvolvimento } \\
\text { Ambiental }\end{array}$} & $\begin{array}{l}\text { Acompanhamento técnico, desenvolvendo } \\
\text { ações de sensibilização, formação e } \\
\text { capacitação voltadas para a preservação } \\
\text { ambiental, com orientação e coordenação da } \\
\text { Direção Executiva da ADEC. }\end{array}$ & \multirow[t]{2}{*}{$\begin{array}{l}\text { Responsabilidade pelo Meio } \\
\text { Ambiente. }\end{array}$} \\
\hline & $\begin{array}{l}\text { Proibido o uso de agrotóxico e de fogo no } \\
\text { roçado. Incentiva o reflorestamento. }\end{array}$ & \\
\hline
\end{tabular}

Fonte: ADEC (2010). em embalagens de tecido ecológico e podem ser reaproveitadas como ecobags. O tamanho das caixas também foi otimizado desde o início da Tênis, em 2004.

A energia elétrica para seus escritórios não é proveniente de centrais nucleares e térmicas, mas se origina da ENERCOOP, um fornecedor de energia verde

A Tênis não faz publicidade paga e estes recursos são economizados e realocados diretamente na cadeia produtiva. Não fazer publicidade permite que seus produtos sejam comercializados a preços equivalentes àqueles de grande marcas (em torno de 100 euros), mesmo que os custos de fabricação e matéria-prima da Tênis sejam 7 ou 8 vezes maior. A divulgação da marca 
é feita por uma equipe interna em redes sociais e com o apoio de artistas e intelectuais em eventos e vernissages. A Tênis não possui estoque e produz sob encomendas com seis meses de antecedência. Isto permite adaptar as quantidades demandadas com as baixas quantidades de algodão agroecológico disponível.

A Tênis apoia uma cooperativa que presta auxílio à comunidade carente, oferecendo oportunidade de emprego e qualificação para jovens adultos. Na cooperativa é ensinado o ofício de sapateiro aos maiores de 18 anos e realizadas ações educativas e inclusivas para crianças. Existem também projetos profissionalizantes para jovens aprendizes, de 14 a 18 anos, que começaram a fazer calçados para a prática de skate.

\section{c) Rede Justa Trama}

A Justa Trama produz roupas para o público adulto e infantil. O fio e o tecido são fabricados em Minas Gerais e as roupas em três estados. Em São Paulo, as roupas infantis, em Santa Catarina as roupas artesanais e, em Porto Alegre as roupas em série. Os botões e acessórios são feitos em Rondônia, onde são aproveitadas sementes da Amazônia para a sua confecção.

Neste cenário, participam da Rede Justa Trama homens e mulheres agricultores, fiadores, tecedores, coletores e beneficiadores de sementes e costureiras. São mais de 700 associados em quatro regiões do Brasil. A associação e as cooperativas cobrem todos os elos da cadeia, do plantio à roupa, e seguem o princípio de preservação do meio ambiente. Além desse princípio, a Justa Trama, pensa no desenvolvimento social das suas comunidades e na geração de emprego e renda. Com a produção direta das cooperativas, consegue agregar valor a todos os elos da cadeia, com ganhos de 50 a 100\% acima do mercado, fazendo assim acontecer uma justa distribuição de renda.

A ADEC é um dos componentes da Rede Justa Trama. A sede da Rede está localizada em um anexo da Cooperativa Unidas Venceremos (UNIVENS) em Porto Alegre, onde é feita a articulação de toda a rede. A Rede Justa Trama produz e vende a sua produção no mercado interno brasileiro e também no exterior, em feiras e por encomenda, por meio de parcerias. A capacitação de todos os integrantes da cadeia é feita de forma constante, tanto para inovações com relação às técnicas de costura como também para os cuidados com as questões ambientais. A cadeia é formada por parceiros solidários, exceto no transporte que ainda é utilizada a logística tradicional. Existe a preocupação em produzir conforme o que a natureza pode oferecer de matéria-prima.

No Quadro 4, foram identificadas as ações realizadas pelas organizações Tênis e Justa Trama, e são apresentadas sugestões para melhorar o apoio dado por elas às ações de mitigação dos efeitos nocivos das mudanças climáticas.

Como pode-se observar, o Quadro 4 demonstra algumas iniciativas tomadas pelas organizações, mas ainda há possibilidades que podem ser exploradas. Dividindo-se a análise em duas macrodimensões: (i) impactos agroambientais e (ii) impactos socioeconômicos das ações vinculadas aos princípios do Comércio Justo, evidenciam-se as suas contribuições para diminuir os efeitos das mudanças climáticas. De antemão, percebese que a macrodimensão relacionada aos impactos agroambientais recebe destaque. Tanto a Tênis como a Justa Trama seguem os princípios das certificadoras de Comércio Justo e orgânico, protegendo o meio ambiente, desenvolvendo práticas agrícolas sustentáveis, sem usar agroquímicos e atuando no planejamento e monitoramento ambiental.

Verificou-se que em seus processos produtivos não são utilizados produtos químicos, potenciais contaminantes do solo, do ar e da água. Este fator contribui para diminuir a emissão de gases de efeito estufa, como o óxido nitroso e o metano, favorecendo a mitigação das consequências nocivas das mudanças climáticas (IPCC, 2007; TEXTILE EXCHANGE, 2012). Além disso, tanto a Tênis quanto a Justa Trama, dão preferência ao uso insumos naturais e recicláveis com a mínima utilização de recursos e geração dos resíduos.

Existem alguns aspectos que merecem atenção e prioridade nas agendas das políticas públicas, como a questão energética. As organizações são dependentes de investimentos estatais para suprir sua demanda, exceto se possuírem uma fonte renovável própria para a geração de 
energia, o que é inviável economicamente, ainda mais se tratando de pequenas empresas. Nesse sentido, no Brasil não são oferecidas alternativas para a compra de energia elétrica proveniente de outra fonte, o que pode ser um gargalo nesse processo.

O transporte também é uma das questões que podem ser melhoradas e representa um desafio para as organizações, já que no Brasil, o transporte interno é predominantemente rodoviário e ainda não existem muitas alternativas a essa modalidade logística. Neste caso, os efeitos podem ser amenizados por meio da otimização da carga, como a redução das embalagens, acondicionando uma maior quantidade de produtos em cada viagem. Outra opção seria a cooperação entre empresas vizinhas de modo que possam utilizar apenas um caminhão para o transporte de várias cargas.

Quadro 4 - Ações da Tênis e da Justa Trama e suas contribuições para a mitigação dos efeitos nocivos das mudanças climáticas.

\begin{tabular}{|c|c|c|}
\hline $\begin{array}{l}\text { Sugestões de resposta } \\
\text { do Comércio Justo às } \\
\text { mudanças climáticas }\end{array}$ & Ações da TÊNIS & Ações da JUSTA TRAMA \\
\hline $\begin{array}{c}\text { Escolher fornecedores } \\
\text { de energia verde e } \\
\text { renovável }\end{array}$ & $\begin{array}{l}\text { Fornecedor de energia verde nos } \\
\text { escritórios na França. }\end{array}$ & $\begin{array}{l}\text { Não há opções, utiliza o fornecimento de } \\
\text { energia elétrica tradicional. }\end{array}$ \\
\hline $\begin{array}{c}\text { Comercializar } \\
\text { produtos artesanais e } \\
\text { uso de recicláveis com } \\
\text { a mínima utilização de } \\
\text { recursos } \\
\end{array}$ & $\begin{array}{l}\text { Embalagens dos tênis e bolsas são } \\
\text { feitos de materiais reciclados, } \\
\text { recicláveis e reaproveitáveis. }\end{array}$ & $\begin{array}{l}\text { A produção é feita de maneira sustentável } \\
\text { com o uso do algodão agroecológico. } \\
\text { Para os botões, colares e acessórios, } \\
\text { utilizam sementes da Amazônia extraídas } \\
\text { de maneira sustentável. }\end{array}$ \\
\hline $\begin{array}{l}\text { Priorizar o transporte } \\
\text { por navio e o comércio } \\
\text { local }\end{array}$ & $\begin{array}{l}\text { Estimulam a contratação de } \\
\text { trabalhadores locais em suas } \\
\text { fábricas; transporte das mercadorias } \\
\text { em navio, quando possível; porém, } \\
\text { apesar da produção ser no Brasil, } \\
\text { não existe comércio interno, as } \\
\text { mercadorias são exportadas. No } \\
\text { Brasil, a matéria-prima usa a } \\
\text { logística tradicional. }\end{array}$ & $\begin{array}{l}\text { As cooperativas geralmente são de } \\
\text { pessoas que moram no próprio bairro, } \\
\text { diminuindo o trajeto de deslocamento dos } \\
\text { trabalhadores. Estimulam também o } \\
\text { trabalho em casa, caso seja mais } \\
\text { conveniente para a costureira. Para as } \\
\text { mercadorias, utilizam o sistema } \\
\text { tradicional de transporte, uma vez que no } \\
\text { Brasil, o principal meio de transporte } \\
\text { ainda é o rodoviário. }\end{array}$ \\
\hline $\begin{array}{c}\text { Ajudar as } \\
\text { comunidades a } \\
\text { preservar as florestas } \\
\text { fornecendo uma saída } \\
\text { para a comercialização } \\
\text { de seus produtos }\end{array}$ & $\begin{array}{l}\text { Utilizam a borracha natural da } \\
\text { Amazônia. Com isso, ajudam a } \\
\text { combater o desmatamento, pois os } \\
\text { seringueiros ajudam a preservar a } \\
\text { sua fonte de renda (as árvores). }\end{array}$ & $\begin{array}{l}\text { Através da ADEC, existe o estímulo para } \\
\text { o reflorestamento das áreas desmatadas } \\
\text { para o plantio do algodão. }\end{array}$ \\
\hline $\begin{array}{c}\begin{array}{c}\text { Apoio à pequena } \\
\text { agricultura orgânica e } \\
\text { sustentável }\end{array} \\
\end{array}$ & $\begin{array}{l}\text { Sim, em conjunto com a ADEC, só } \\
\text { utilizam algodão orgânico. }\end{array}$ & $\begin{array}{l}\text { Sim, em conjunto com a ADEC, só } \\
\text { utilizam algodão orgânico e produtos com } \\
\text { apelo ecológico e de cooperativas. }\end{array}$ \\
\hline
\end{tabular}

Fonte: Adaptado de Plate-forme Pour le Commerce Équitable (2010).
No que tange a macrodimensão, vinculada aos impactos socioeconômicos, constata-se que há avanços. As duas organizações priorizam a contratação de trabalhadores locais e que residam no próprio bairro, ou até mesmo que desenvolvam suas atividades profissionais em casa, como é o caso da Justa Trama. Esta característica beneficia especialmente as mulheres que podem trabalhar sem afastar-se da família, tal fato contribuiu para o sucesso desta Rede, que teve seu início a partir de uma cooperativa composta apenas por mulheres.

Outros avanços promovidos pela prática dos princípios de Comércio Justo que merecem destaque são: incremento e diversificação de rendimentos, promovendo desenvolvimento econômico local; coesão social, a partir de melhores condições de trabalho e convivência; aumento da autoestima dos trabalhadores, contando com ações de conscientização e prevenção de problemas sociais enfrentados pela c o munid a d e ; transparência na organização da produção e na comunicaçãoentre toda a cadeia; e, incremento na saúde e segurança no trabalho, uma vez que não utilizam produtos tóxicos.

No entanto, existem carências que podem ser trabalhadas. Em termoscomerciais, a Tênis poderia vender também no mercado interno, para reduzir a pegada ecológica de seus produtos e valorizar o comércio e 
os consumidores locais. Além disso, o investimento em parcerias com instituições de ensino e pesquisa é uma iniciativa que pode oportunizar a fabricação de pesticidas biológicos capazes de favorecer a produtividade e a qualidade do algodão, bem como contribuir com o crescimento dos mercados locais. Isso tende a reforçar o ganho em qualidade de vida, saúde, segurança alimentar e bem-estar, além de manter os trabalhadores em suas regiões devido às melhores condições de renda, perspectivas de emprego, habitação e crescimento coletivo. Contribuindo, assim, para que a produção do algodão agroecológico ganhe ainda mais fôlego, consequentemente reduzindo os efeitos das mudanças climáticas no planeta.

Esses resultados vão ao encontro do que é afirmado por Raynolds (2012) acerca do Comércio Justo. As instituições envolvidas em seus princípios e práticas realizam esforços para conduzir o comércio com base em valores relacionais e cívicos, constantemente desafiados, mas não subordinados, por forças econômicas dominantes. Neste sentido, o Comércio Justo pode ser visto como um contra-movimento que desafia regras capitalistas tradicionais ao propor um novo tipo de relação entre produtores e consumidores. Assim, relaciona-se intrinsecamente com o combate às mudanças climáticas, que depende de um novo tipo de produção.

\section{Considerações Finais}

Com este estudo procurou-se identificar como as práticas do Comércio Justo podem contribuir para a mitigação dos efeitos nocivos das mudanças climáticas. Os resultados sugerem que o Comércio Justo pode ser uma alternativa capaz de amenizar os efeitos nocivos da produção em grande escala e intensiva no uso de agroquímicos. Por meio do pagamento de um preço equitativo e de relações comerciais de longo prazo, este comércio prioriza o meio ambiente e as pessoas, mantendo os produtores na propriedade rural. Além disso, estimula o uso sustentável dos recursos naturais e promove uma conscientização de que os impactos ambientais podem ser evitados pela capacidade que os consumidores possuem de escolher o que será consumido.

Conforme observado nos casos apresentados, há esforço por parte das organizações para informar sobre o consumo consciente no Brasil. Com isso, busca-se atrair mais consumidores de produtos ecológicos, apoiando os produtores que utilizem técnicas sustentáveis de produção com menor agressão ao meio ambiente. Estas atitudes corroboram com o esforço para controlar e mitigar os efeitos das mudanças climáticas.

Graves problemas causados pelas mudanças climáticas, como por exemplo, a falta de alimentos, podem ser solucionados ou amenizados com a adoção de práticas agrícolas sustentáveis apoiadas pelo Comércio Justo. Alguns dos casos práticos abordados na etapa exploratória, como o dos produtores de banana e de arroz, demonstraram boas soluções de adaptação às mudanças climáticas e consequente redução dos seus impactos. Destaca-se que, além da agroecologia, identificou-se, na etapa descritiva, a preocupação das organizações com outros aspectos. A Tênis, por exemplo, mostrou que considera com atenção a escolha dos meios de transporte, das embalagens e dos recursos de energia que consome.

Outra questão que vem à tona neste contexto é a relação entre crescimento econômico, alterações climáticas e custos para a mitigação dos seus efeitos. Ou seja, deve-se pensar não só em crescimento, mas em desenvolvimento econômico, sob o risco de provocar alterações climáticas muito difíceis e onerosas para reverter. Nesse sentido destaca-se, mais uma vez, que é importante que as emissões sejam reduzidas no processo produtivo e que haja a prevenção dos danos, não apenas que se trabalhe para amenizar os seus efeitos. A Tênis, por meio das ações supracitadas, demonstrou seu esforço para reduzir suas emissões de gases de efeito estufa.

Conforme os resultados, percebe-se que a participação dos cooperados e membros das associações que trabalham de acordo com os princípios do Comércio Justo é bastante valorizada. É exigido que os produtores cumpram as normas de preservação do meio ambiente e, em contrapartida, recebem o apoio para que consigam melhorar o seu bem estar e o de suas famílias. Inseridos neste cenário de integração das associações e dentro das cadeias produtivas, vários outros movimentos ganham força, como o dos produtos orgânicos e o turismo justo.

Constatou-se que o Comércio Justo pode contribuir, 
por defender a indissociabilidade do meio ambiente e do desenvolvimento humano, para limitar a emissão de gases poluentes e incentivar os compromissos econômicos, sociais e ambientais perante as práticas agrícolas. Os atores do Comércio Justo se mobilizam para atenuar os efeitos do desregramento do clima, apoiando a proteção do meio ambiente e a manutenção das condições razoáveis de remuneração para os pequenos produtores.

Porém, conforme destacado nos resultados, são necessários avanços nas práticas das organizações de Comércio Justo, que poderiam contribuir ainda mais para a mitigação dos efeitos danosos das mudanças climáticas. Como visto, algumas vezes estes avanços não dependem apenas das organizações, como é o caso do fornecimento de energia que está atrelado ao investimento estatal, ou no uso de modos alternativos de transporte, uma restrição devido à predominante malha rodoviária brasileira. No entanto, ações como a inserção no mercado interno pela Tênis ou o uso cooperado do transporte rodoviário no Brasil poderiam ser realizados.

Outra constatação interessante é o maior número de ações realizadas pela ADEC, organização que trabalha diretamente com a produção do algodão agroecológico e integra a cadeia da Justa Trama e da Tênis. Essa característica justifica-se devido ao fato de que as organizações em geral, e especificamente nos casos estudados, acabam atuando de maneira mais intensiva nos elos onde o impacto gerado e sofrido é mais direto, como é o caso da produção. Dessa forma, percebe-se que mesmo na ótica do Comércio Justo, que busca uma visão holística da cadeia, ainda existem deficiências a serem superadas.

Essa constatação vai ao encontro da afirmação de Raynolds (2012). Para a autora, embora o alcance de tudo o que é preconizado pela visão de Comércio Justo ainda esteja longe de ser completo, os desafios que emergem podem informar uma série de movimentos progressistas da sociedade civil que busca ir além da crítica de promover novas arenas da economia social. Assim, pode-se afirmar que os princípios do Comércio Justo têm capacidade para auxiliar no desenvolvimento local sustentável, o que inclui a mitigação dos efeitos climáticos, e que se procurou demonstrar, por meio das práticas apresentadas e discutidas nesta investigação. Enfim, há desafios a serem enfrentados, bem como existem oportunidades a serem exploradas.

Finalmente, não foram encontrados dados quantitativos que comparam as duas formas de produção (convencional e agroecológica) em termos de impactos nas mudanças climáticas, dessa forma, como sugestão de pesquisas futuras, pode ser feita a quantificação e comparação dos dados de emissões de produtos produzidos e comercializados na forma tradicional com aqueles produzidos dentro dos princípios do Comércio Justo. Outra questão que pode ser investigada é sobre qual é o conhecimento da população sobre o que é a pegada ecológica e o que são emissões de carbono.

\section{REFERÊNCIAS}

ADEC - Associação de Desenvolvimento Educacional e Cultural de Tauá. Plano ambiental da ADEC 2010. Tauá, 2010.

AMÉRICO, Carlos. Brasil já tem R\$ 200 milhões para combater os efeitos das mudanças climáticas. Instituto Carbono Brasil. Disponível em: $<$ http://www.institutocarbonobrasil.org.br/\#noticias2/ noticia=725815 $>$. Acesso em: 25 agosto 2010.

ASSAD, Eduardo; PINTO, Hilton Silveira. Aquecimento global e a nova geografia da produção agrícola no Brasil. São Paulo, ago., 2008.

CLARKE, N. et al. The Political Rationalities of Fair-Trade Consumption in the United Kingdom. Politics \& Society, v. 35, n. 4, p. 583-607, dez. 2007. <http:// dx.doi.org/10.1177/0032329207308178>

DE PELSMACKER, P.; JANSSENS, W. A model for fair trade buying behaviour: the role of perceived quantity and quality of information and of productspecific attitudes. Journal of Business Ethics, v. 75, n. 4, p. 361-380, 2007. <http://dx.doi.org/10.1007/s10551006-9259-2>

DORAN, C. J.; NATALE, S. N. The Role of Religion 
in Fair Trade Consumption. Journal of Business Ethics, v. 98, n. 1, p. 1-15, 2011. <http://dx.doi.org/10.1007/ s10551-010-0533-y>

ENERCOOP. Fournisseur d'életricité verte. Disponível em: <http://www.enercoop.fr/. Acesso em: 20 jun. 2010>.

FAIRTRADE FOUNDATION. More on cotton. Disponível em: < http://www.fairtrade.org.uk/products/ cotton/more_on_cotton.aspx>. Acesso em: 18 nov. 2010.

FAIRTRADE INTERNATIONAL (FLO). Disponível em: <http://www.fairtrade.net/aims_of_ fairtrade_standards.html>. Acesso em: 20 maio 2010.

FAIRTRADE INTERNATIONAL (FLO). Boost for Fairtrade in Brazil. Disponível em:http://www. fairtrade.net/single_view1.0.html?\&cHash=bba9084d39 \&tx_ttnews[tt_news]=201>. Acesso em: 28 abr. 2011.

FAIRTRADE INTERNATIONAL (FLO). Challenge and Opportunity: Supplement to Annual Review 2010 e 11. FLO, Bonn, 2011b.

FRETEL, A. C.; SIMONCELLI-BOURQUE, E. O Comércio Justo e o Consumo Ético. Rio de Janeiro: DP\&A Fase, 2003.

FRIDELL, G. The Fair Trade Network in Historical Perspective. Canadian Journal of Development Studies, v. 25, n. 3, p. 411-428, 2004. <http://hdrnet. org/117/1/Fridell.pdf>

HELM, Dieter. Climate-change policy: why has so little been achieved?. Oxford Review of Economic Policy, v. 24, n. 2, p. 211-238, 2008. <http://dx.doi. org/10.1093/oxrep/grn014>

IFOAM - International Federation of Organic Agriculture Movements. Definition of Organic Agriculture. Disponível em: <http://www.ifoam.org/ growing_organic/definitions/doa/index.html>. Acesso em: 15 jul. 2011.

IPCC - Intergovernmental Panel on Climate Change. Climate Change 2007: synthesis report. Fourth
Assessment Report. Disponível em:< http://www.ipcc. ch/pdf/assessment-report/ar4/syr/ar4_syr.pdf>. Acesso em: 28 ago. 2012.

JUSTA TRAMA. Disponível em:< http://www. justatrama.com.br/pt/home/index.php>. Acesso em: 10 out. 2009.

LE LABORATOIRE DU COMMERCE EQUITABLE. Orfsc thai jasmine rice supply chain. Auditoria realizada em agosto de 2008. Disponível em: <http://www.laboequitable.fr/sur-le-terrain/lescooperatives/3-orfsc.html>. Acesso em: 10 ago. 2010.

LIMA, P. J. B. F.; SOUZA, M. C. M. Produção brasileira de algodão orgânico e agroecológico em 2006. Disponível em: <http://www.esplar.org.br/artigos/2007/ agosto/algodao_agroecologico.pdf $>$. Acesso em: 16 jul. 2010.

McMURTRY, J. J. Ethical Value-Added: Fair Trade and the Case of Café Femenino. Journal of Business Ethics, v. 86, p. 27-49, 2009. <http://dx.doi.org/10.1007/ s10551-008-9760-X>

NABI, G.; MULLINS, C. E. Soil Temperature Dependent Growth of Cotton Seedlings Before Emergence. Pedosphere, v. 18, n. 1, p. 54-59, 2008. < http://dx.doi.org/10.1016/S1002-0160(07)60102-7>

NELSON, V. et al. Climate Change, Agricultural Adaptation and Fairtrade: identifying the challenges and opportunities. University of Greenwich's Natural Resources Institute. May, 2010.

ORGANIC EXCHANGE. Organic Cotton Market Report 2009. Executive Summary, 2010.

PLATE-FORME POUR LE COMMERCE ÉQUITABLE. Commerce équitable et justice climatique. Les Carnets de la Plate-Forme pour le Commerce Équitable. Paris, 2010.

RAYNOLDS, L. T. Re-embedding global agriculture: the international organic and fair trade movements. Agriculture and Human Values, v. 17, n.3, p. 297-309, 2000. <http://dx.doi.org/10.1023/A:1007608805843> 
RAYNOLDS, L. T. Consumer/producer links in fair trade coffee networks. Sociologia Ruralis, v. 42, n. 4, p. 404-424, 2002. <http://dx.doi.org/10.1111/14679523.00224>

RAYNOLDS, L. T. Fair Trade: Social regulation in global food markets. Journal of Rural Studies, v. 28, p. 276-287, 2012. <http://dx.doi.org/10.1016/j. jrurstud.2012.03.004>

RENARD, M. C. Quality certification, regulation and power in fair trade. Journal of Rural Studies, v. 21, n. 4, p. 419-431, 2005. <http://dx.doi.org/10.1016/j. jrurstud.2005.09.002>

TAVARES, M. N. A. et al. A volta do ouro branco: a revitalização da cultura algodoeira herbácea no sítio lagoa de dentro. Informativo técnico do semi-árido (INTESA), v.3, n.1, p.23-36, 2010

TÊNIS - Ecological Fair Trade. Disponível em:< http://www.tênis-fairtrade.com/>. Acesso em: 10 out. 2010.

TEXTILE EXCHANGE. The Beginner's Guide to Sustainable Fibers. Sample, Versão 1, mar., 2011.

TEXTILE EXCHANGE. Benefits of Organic. Disponível em: <http://farmhub.textileexchange.org/ learning-zone/all-about-organic-cotton/benefits-oforganic>. Acesso: 28 ago. 2012.

TRUSCOTT, L. et al. 2010 FARM \& FIBER REPORT: Organic by Choice. Textile Exchange, 2010.

VIEIRA, Marcelo M. F. Por uma boa pesquisa (qualitativa) em administração. In: VIEIRA, Marcelo M. F.; ZOUAIN, Deborah M. (Orgs.). Pesquisa qualitativa em administração. 2. ed. Rio de Janeiro: FGV, p. 13-28, 2006.

ZARIOH, N. Étude des effets et de l'impact du commerce equitable labellisé en République Dominicaine: étude de cas de l'organization de producteurs Banelino. Paris: Max Havelaar France, 2007. 